\title{
The Supporting Role of Scientific Research in the Teaching of Colleges and Universities
}

\author{
Yao-hui CHEN*, Xin-yu LIU and Zhi-guo LIU
}

School of Economics, Nanjing University of Finance \& Economics, Nanjing, Jiangsu, China

${ }^{*}$ Corresponding author

Keywords: Scientific Research; College Teaching; Talent Training.

\begin{abstract}
Scientific research and teaching are two important tasks of college education, but there are two misunderstandings in dealing with teaching and scientific research. On the one hand, it focuses on research and neglects teaching. On the other hand, it believes that scientific research has little influence on teaching quality. Teachers can play their roles in college without engaging in scientific research. In fact, scientific research promotes teaching, improves the quality of teachers, and enriches teaching content, which are conducive to developing students' innovative thinking. In order to effectively promote teaching by research, it has to figure out that one of the purposes of scientific research lies in teaching. It is necessary to change the evaluation criteria for research and teaching, organize scientific teams to enhance the overall research level, and apply the research results into extra-curricular practice teaching.
\end{abstract}

\section{Introduction}

Teaching and scientific research are the works of every teacher in colleges and universities. One important aspect that the college teacher differs from the primary and secondary school teacher is that the former is not only the transmitter of knowledge, but also the researcher who leads students to explore unknown areas and create knowledge while teaching. This requires a high level of knowledge and creativity of college teachers, who can take the dual responsibilities of teaching and research. In 2015, the State Council issued the "Overall Scheme to Integratedly Promote the Construction of World-Class Universities and Disciplines", proposed to cultivate top innovative talents and accelerate the reform of the personnel training model, promote the joint education of science and teaching, and improve the training mechanism for high-level innovative talents supported by scientific research. Therefore, the entire scientific research level of a university is closely related to the overall quality of teaching and personnel training.

Many scholars in China have conducted empirical analysis of the relationship between scientific research and teaching. Lu Genshu et al. (2005) collected the relevant data of our college on teaching and research in recent years to show that there was a positive correlation between talent training and scientific research in universities [1]. According to the research conducted by Wei Hong et al. (2006), the contribution rate of classroom teaching to higher education personnel training was 30\%. Teachers' research achievements played a great role in promoting their teaching [2]. Wang Fei and Wang Yunlai (2016) believed that the duty of college teachers lay in research and teaching. Research is "first digestion", and teaching is "second digestion"; research is "profound", and teaching is to make it "easy to understand" [3]. Scientific research plays an important role in promoting teaching. Raising the level of scientific research, promoting teaching and cultivating innovative talents is a major task of colleges and universities.

From the management and practice of higher education in our country, universities and colleges generally attach importance to teaching and scientific research. However, there are still some misunderstandings in the understanding and practice of how to correctly handle the relationship between scientific research and teaching, thus affecting the promotion of scientific research on teaching to a certain extent.

One misunderstanding is the highly emphasis on the role of scientific research, which directly equates scientific research ability with teaching ability. In terms of the evaluation indicators, 
scientific research can better represent the ability of teachers. Therefore, scientific research becomes the key indicator for teachers' evaluation. In the evaluation system for teachers, although emphasis is placed on teaching, or both teaching and research are equally important, in practice, the preference of scientific research in universities is more important. In the policy orientation and evaluation mechanism of the school, financial, material, and human resources are all provided to support scientific research. The school's deliberate pursuit of scientific research achievements leads to the loss of teaching value. The evaluation of teachers' ability in colleges also focuses on scientific research. The reward policies, the assessment of professional titles, and the evaluation of teacher's abilities are all based on the teachers' published papers, research projects, and various types of awards.

The other misunderstanding is the opinion that excellent college teachers do not need to engage in scientific research as long as they do well in teaching. It is believed that the teaching quality has no relation to the research level. Scientific research has little effect on teaching. In practice, there are two situations: firstly, some teachers with lower level of scientific research almost have no published papers, but their teaching abilities have been widely recognized by students and they have won praises from students in the evaluation. Secondly, on the contrary, for others with higher level of scientific research, their teaching qualities are not recognized by students. Therefore, many teachers hold that if they are not good at scientific research, they can engage in teaching. Schools should not assess their scientific research capabilities and set some mandatory requirements. Scientific research distracts teachers from teaching, which is also not beneficial for teaching.

Can college teaching quality be ensured without scientific research? Cai Yuan-pei, a famous educator, classified college teachers into three types: "teaching without learning", "learning without teaching" and "not teaching without learning". Those who teach but do not learn will not engage in academic research and they teach outdated things year after year, leading to obsolete teaching contents and rigid teaching methods. Due to the lack of scientific research and teaching innovation, it directly affects students' grasp of the frontier knowledge and the development of their innovative thinking. One of the most important tasks of college education is to impart new knowledge to guide students to think more deeply. But this is often less reflected in the teaching quality evaluation system.

\section{The Role of Scientific Research in Supporting and Promoting Teaching Quality}

With the progress of the times, college teachers should not only teach, but also create knowledge as well as a new culture in the future. This is also an important symbol of higher education that distinguishes it from elementary education. The basic value function of colleges and universities in talents training and knowledge transmission determines that scientific research activities focus on discovering new knowledge, creating new disciplines, and developing students' abilities of creativity and exploration. The task of higher education determines that scientific research should account for much more in the work of teachers. On the basis of teaching, teachers need to put more efforts in research to really improve their teaching quality. The antagonism between teaching and scientific research is not conducive to the improvement of scientific research achievements, and the importance of research achievements is belittled.

Firstly, the role of scientific research in the promotion of teaching is manifested in the fact that it can improve teachers' knowledge and teaching ability. Research work is an important way to enhance the quality of college teachers. Each link of scientific research helps teachers master the development trends, characteristics, research methods of disciplines, and the relations with others. Scientific research is the process of teachers' self-improvement and development. Through the research work, teachers' knowledge structure and system have been enhanced. And they can better grasp the frontiers of knowledge, which lays the foundation for the reform of teaching contents and methods. Scientific research helps teachers improve their academic level, so that they can increase their understanding of the teaching content. It also helps change the phenomenon of just repeating what the books say so as to achieve better teaching effects [4].

Secondly, scientific research is beneficial to enrich teaching contents. The teaching task of 
college teachers is to impart the scientific discoveries and achievements of predecessors or others to the students. At the same time, they should also integrate new findings and new ideas of researches into the teaching process, which are often close to reality and are more vivid and novel than the knowledge in books. In colleges, scientific research and teaching have a relationship of source and course. Without scientific research support, teaching is like water without a source, and a tree without roots. Teachers must carry out a large amount of literature review and reading in scientific research. In this case, they are aware of the latest achievements of academic research at home and abroad, so that they can have a certain academic level in teaching. Through scientific research, teachers can introduce new theories, methods and achievements into teaching, thus promoting the reform of teaching contents, which forms a classroom teaching system with high theoretical level, rich contents, strong practicability, and distinctive features. Scientific research makes the teaching contents of teachers have their own innovative views and research results, which can not only cultivate students' innovative ability, but also stimulate their interest in learning, thus improving the teaching effects.

Thirdly, teachers' scientific research helps develop students' thinking abilities, expand their horizons, and improve their qualities. Teachers' research experience and grasp of the nature of the research object, process and characteristics can effectively guide students to carry out innovative activities. Without the experience in scientific research, it is of no use to develop their innovative ability. Liu Xuedong and Wang Xia took Stanford University as an example to illustrate the relationship between teaching and scientific research [5]. The professor of Economics conveys not only the knowledge of economics, but also its social value with his academic achievements. This is difficult for teachers who do not have a certain level of scientific research.

Teachers' scientific research plays an important role in cultivating students' innovative ability through three ways: one is the way teachers think about problems. In teaching, teachers provide a learning template for developing students' logical thinking ability when demonstrating their new findings in scientific research, which can improve students' learning and research ability, and guide them from passive learning to active knowledge construction. The second is that the research will affect students' attitudes towards scientific knowledge and the shaping and cultivation of their sound personality. Scientific research is a tedious activity that requires a lot of hard work. It is an exercise for the teacher who is engaged in scientific research, which will also be permeated into their teaching and affect the cultivation of students' qualities. For the third way, through teachers' scientific research, it can create a good academic atmosphere and form a realistic and pragmatic environment. The combination of research and teaching, and students' wide participation, are conducive to an active academic atmosphere, which will stimulate students' curiosity and initiative to develop their consciousness of independent exploration and rigorous scientific attitude.

Scientific research can improve the quality of teaching, and the opposition between scientific research and teaching will affect the improvement of teaching quality and the cultivation of innovative talents (ibid). Jaspers described the relationship between teaching and scientific research as following, "The best researchers are the best teachers. Only in this way can researchers lead people to the real process of knowledge pursuit and even the spirit of science. Only these researchers are learning lively, and they present the nature of science. Through their guidance, the same motivation arises in the minds of students" [6].

\section{Effective Measures to Promote Teaching by Scientific Research}

From the practice of all kinds of colleges and universities, they have paid great attention to scientific research, but rarely take effective measures to promote teaching by scientific research. It is basically in a state of laissez faire that whether teachers engaged in scientific research apply research achievements to teaching and how much they apply to teaching. This is determined by their own understanding. In order to better serve scientific research teaching and improve the teaching quality, the measures can be taken as follows. 


\subsection{Making clear that the purpose of scientific research is to serve the teaching}

The status of college teachers determines that, through the research work, they not only serve the social and economic construction, or obtain more material benefits, but also have to promote the improvement of teaching quality, serve the teaching and cultivate innovative talents, which are the most direct influence of scientific research. If only the research task that is completely disjointed with teaching is completed, to some extent, it also deviates from the purpose of teachers' scientific research. Therefore, teachers' scientific research should be beneficial to teaching and personnel training. And they are supposed to choose research directions, arrange research work, and organize relevant activities.

Teachers are required to carry out teaching as well as scientific research, engaging in basic research which is closely related to their own teaching. The important theories and practical problems in teaching have to be explored. This is not a burden but a knowledge preparation for teaching. For teachers, the conflict of time and energy in teaching and research will also be eased.

\subsection{Changing evaluation standards for teaching and scientific research}

First of all, in terms of the design of teaching evaluation standards, it must account for a large proportion of teaching contents. Teaching evaluation should not only focus on the external performance of "teaching ability", such as language use, coherence, PPT, and teaching plans. College teachers do not need to make any innovation in teaching according to such standards, which deviates from the original intention of cultivating innovative talents. This has exerted negative effects in guiding teachers' teaching and scientific research. Besides, evaluation standards for research are not scientific. Most schools' evaluation of teachers' scientific research level is mainly based on the number of their published papers, the level of periodicals and the projects, and research funds. In addition to these standards, the peer evaluation of working papers can be introduced to reduce the threshold of scientific research to a certain extent, and at the same time make more scientific evaluation standards.

\subsection{Organizing scientific research teams to improve the overall teaching and research level of teachers}

In a teaching team, if teachers differ from each other in the level of research and teaching, academic leaders of various disciplines must take corresponding responsibilities to organize teachers to conduct scientific research. The leaders are the organizers of research projects who make frameworks and strategies, while other teachers carry out specific research work under the guidance of professors. As a teaching team constantly contacts with each other and organizes discussions on theoretical and practical issues, various ideas collide with each other. Teachers with strong scientific research ability will play a leading role in improving the overall level.

\subsection{Applying scientific research achievements in guiding extracurricular teaching and practice}

In the practice of extra-curricular teaching, teachers' research achievements are more targeted and play a more important role in the cultivation of students' ability. It can be realized in the following ways.

(1) To Change the Organizational Form of Classroom Teaching and Carry out Research-based Learning

In the classroom teaching, the cramming method of teaching must be changed to improve the quality of teachers. Teachers are only required to highlight the key and difficult points in teaching and students need to find the information themselves and learn to self-study and think independently.

(2) To Strengthen the Graduation Thesis (Design) and Improve Students' Innovative Thinking Ability

Teachers should not only engage in research activities, but also encourage students to participate in scientific research. In the arrangement of tutors for graduation thesis (design), attention should be 
paid to the combination of teachers' research field and students' learning interests. Teachers' scientific research can play a better role in the graduation thesis (design).

(3) To Promote the Tutorial System and Lecture System

Tutors mainly provide learning and academic guidance for undergraduates, offering an opportunity for individual talks between teachers and students. Their academic level and personal charm will play a guiding role in the growth of students. Besides, the discussion in academic lectures will be more helpful to inspire students to think.

\section{Conclusion}

In recent years, the heavy burden of scientific research and the improper assessment have caused a backlash among college teachers, who think that the research task makes it difficult for them to concentrate on teaching, thus seriously affecting the quality of teaching. In fact, this kind of reason is untenable. It puts the scientific research and teaching in opposition. In college teaching, scientific research plays a supporting role in teaching. Without high-quality research, there will be no high-quality teaching. And teachers will have no independent thinking and knowledge innovation. Without scientific research, the teaching is like a tree without roots. The teaching skills, such as language expression, courseware production, blackboard writing and teaching organization, have become an empty formalism. Certainly, the research input is different in research-oriented, teaching-oriented, and teaching and research-oriented colleges and universities. Even for teaching-oriented colleges, it cannot deny the role of scientific research in promoting teaching.

\section{Acknowledgements}

Authors are grateful to the Brand Major Construction Project of University in Jiangsu (PPZY2015B103); Teaching Reform Project of Jiangsu (2017JSJG047); Project of Evaluation Committee of Higher Education Society in Jiangsu (Pgwyh07101); Teaching Reform Project of Nanjing University of Finance and Economics (JGZ1805).

\section{References}

[1] G.S., Lu et al. The Relationship between Research and Teaching in Chinese Higher Education Institute: Empirical Analysis [J]. Research in Teaching, Vol. (4), 2005.

[2] H., Wei et al. Study on the Relation between Research Productivity and Teaching Effectiveness in University [J]. Psychological Development and Education, 2006, (2) 85-88.

[3] F., Wang and Y.L., Wang. "First Digestion" and "Second Digestion"-Discussion on the relationship between university teachers' scientific research and teaching logic [J]. China University Teaching, 2016, (5) 15-18. (In Chinese)

[4] Y.J., Chen. Rebalance of Contradictions between Teaching and Scientific Research from the Perspective of Undergraduate Teaching Audit Assessment [J]. Journal of Kunming University of Science and Technology (Social Science Edition), 2016, 16 (4) 78-87.

[5] X.D., Liu and X., Wang. Course, Teaching, and Research: An Analysis of Undergraduate Talent Cultivation in Stanford University [J]. Higher Education Exploration, 2016, (11) 52-56. (In Chinese)

[6] Jaspers, Karl. Was ist Erziehung? In J. Zou (Trans.). Beijing: SDX Joint Publishing Company, 1991. 